\title{
Staining of Urinary Sediment Constituents
}

\subsection{Staining Techniques}

\subsubsection{From the KOVA ${ }^{\circ}$ System: Staining Solution (Sternheimer-Malbin Solution)} (Fig. 8.1)

- Staining solution: Ethanol, crystal violet, safranin O, and ammonium oxalate.

- Shelf-life: Room temperature, no filtration needed.

- Performance: Between 1 and 2 drops of staining solution are added to $1 \mathrm{ml}$ of urine sediment and carefully mixed; microscopy analysis can be performed immediately.

- Staining result: See product information leaflet.

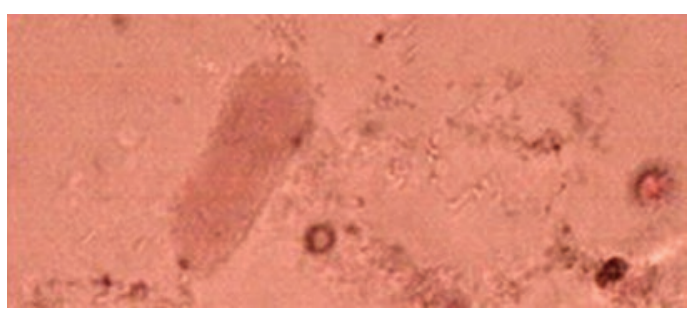

Fig. 8.1 $\mathrm{KOVA}^{\circledR}$ stain

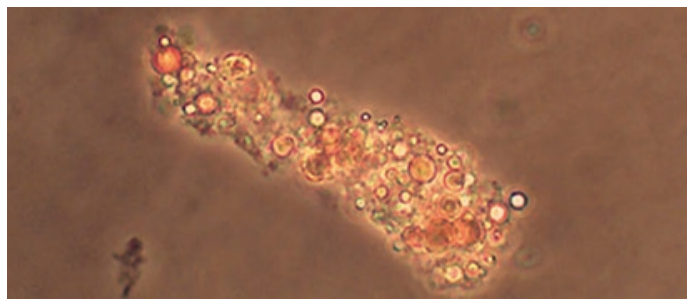

Fig. 8.2 Fat staining with Sudan IV

\subsubsection{Fat Staining (Fig. 8.2)}

- Staining solution: Sudan IV.

- Shelf-life: Room temperature.

- Performance: Between 1 and 2 drops of filtered staining solution are added to $1 \mathrm{ml}$ of urine sediment and carefully mixed; microscopy analysis can be performed immediately.

- Staining result: Fat stains yellowish-red.

\subsubsection{Papanicolaou Stain (Complex Stain)} (Fig. 8.3)

- For urine cytology and erythrocyte morphology.

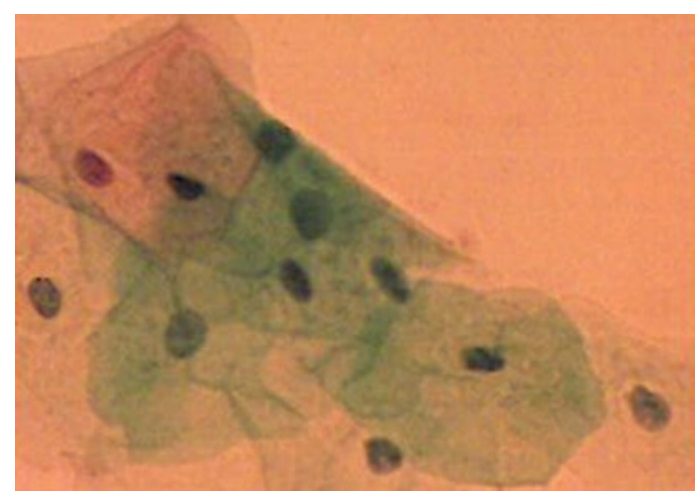

Fig. 8.3 Papanicolaou staining 